\title{
Fabrication of Magnetic Lignin-based Adsorbent for Removal of Methyl Orange Dye from Aqueous Solution
}

\begin{abstract}
Chao Cao, ${ }^{\mathrm{a}}$ Lupeng Shao, ${ }^{\mathrm{a}, \mathrm{b}, *}$ Lucian A. Lucia, ${ }^{\mathrm{a}, \mathrm{c}}$ and Yu Liu ${ }^{\mathrm{a}, *}$
Magnetic lignin-based adsorbent (MLA) was successfully fabricated to remove methyl orange dye from aqueous solution. The synthesized MLA was characterized by means of Fourier transform infrared spectroscopy (FTIR), X-ray diffraction (XRD), $\mathrm{N}_{2}$ adsorption-desorption, scanning electron microscopy (SEM), and vibrating sample magnetometer (VSM). In the process of adsorption, influence factors and recycling performance were considered, and the adsorption mechanisms such as isotherm and kinetics were investigated. The result showed that the equilibrium data was consisted with the Langmuir model with a maximum adsorption capacity of $85.0 \mathrm{mg} / \mathrm{g}$. The adsorption kinetics followed a pseudo-secondorder model. Based the adsorption performance, MLA showed good recyclability. Therefore, these results demonstrate that MLA could offer a great potential as an efficient and reusable adsorbent in the wastewater treatments.
\end{abstract}

Keywords: Lignin; Magnetism; Adsorption; Methyl orange; Regeneration

Contact information: a: State Key Laboratory of Biobased Material and Green Papermaking, Qilu University of Technology, Shandong Academy of Sciences, Jinan, Shandong 250353, China; b: Shandong Chenming Paper Holdings Ltd, Weifang, Shandong 262705, China; c: Department of Forest Biomaterials, North Carolina State University, Box 8005, Raleigh, NC 27695-8005, USA;

*Corresponding author: shaolp@qlu.edu.cn; leoliuyu@163.com

\section{INTRODUCTION}

Dyes are widely used in textile, paper, plastics, rubber, cosmetics and other industries, resulting in the discharge of wastewater that still contains some residual dyes (Carneiro et al. 2010). Dyes generally have some complex organic compounds that are toxic (Yagub et al. 2014; Yang et al. 2018). Due to the negative effect of dyes in water on the photosynthetic rate of hydrophytes and on the health of human beings, the waste streams must be treated prior to discharge into environment (Nair et al. 2014; Banerjee et al. 2019). A variety of processing techniques for removal of dyes from wastewater have been adopted, such as biodegradation, flocculation, membrane filtration, adsorption, and ion exchange, etc. (Liu et al. 2017; Song et al. 2017). Generally, adsorption technology is regarded as an environmentally friendly and feasible method for the advantages of high efficiency, easy operation, low cost, and not producing secondary pollution (Kaykhaii et al. 2018). According to reports, the adsorbents used in dye wastewater treatment mainly include bentonite and clay, activated carbon, synthetic polymer, and nanocomposites (Essandoh and Garcia 2018). In recent years, biomass-based adsorbents derived from lowcost, abundant, and renewable biomass have received considerable attention for the removal of dyes (Liu et al. 2015; Wang et al. 2018).

Lignin, the most abundant natural aromatic polymer on earth, is primarily composed of three phenylpropane units, which are syringyl (S) units, guaiacyl (G) units, and p-hydroxyphenol (H) units (Shuai et al. 2016). Annually, more than 70 million tons of 
commercial lignin is generated from pulping industries and biorefineries. The majority of commercial lignin is burned for power and heat generation, whereas less than $10 \%$ of commercial lignin is used for high value-added applications (Xu et al. 2014; Shao et al. 2018). The development of lignin-based materials with high performance has been gaining more and more attention, which not only diversifies the products, but also encourages the utilization of waste as part of the development of circular economies (Kazzaz et al. 2019; Supanchaiyamat et al. 2019). Especially, preparation of lignin-based adsorbent opens up a new application area for dye wastewater treatment (Wang et al. 2018; Li et al. 2019).

A large number of studies have been dedicated to the investigation of removal of dyes from wastewater using lignin or its derivatives as adsorbents (Zhai et al. 2020). Studies suggest that adsorption capacity of lignin-based adsorbent relies on the pore structure and oxygen functional groups, such as carboxyl and phenolic hydroxyl groups, which can absorb dyes by physicochemical interactions (Guo et al. 2008; Aro and Fatehi 2017; González-López et al. 2020). However, for most lignin-based adsorbents, the saturated adsorption capacity for dyes was not high enough. Moreover, separation and recycling of adsorbents after adsorption is an additional burden, which would limit its application (Zhang et al. 2012). As a consequence, further investigation of recyclable lignin-based adsorbents with high adsorption capacity for wastewater treatment is developed. Magnetic separation technology is considered a proven method to address this issue for the reason that magnetic adsorbent can be easily separated from the aqueous solutions in magnetic field (Chen et al. 2015; Zhang et al. 2019). Therefore, more researchers have focused on the preparation of magnetic lignin-based adsorbents. Geng et al. (2019) prepared magnetic lignosulfonate for wastewater treatment, and the desorption efficiencies of $\mathrm{Cr}(\mathrm{VI})$ and Rhodamine B could reach more than $70 \%$ and $85 \%$ after five regeneration cycles. Li et al. (2018) prepared responsive lignin-coated $\mathrm{Fe}_{3} \mathrm{O}_{4}$ nanoparticles to gain a good adsorption capacity for cationic and anionic dyes. The result showed that the dye-loaded adsorbents could be regenerated by simply adjusting the $\mathrm{pH}$.

In this study, magnetic lignin-based adsorbent (MLA) was prepared for adsorption of methyl orange. During the preparation process, lignin was first coated onto the surface of iron oxide through precipitation, creating a lignin-iron oxide complex. Then the complex was calcined in the tube furnace to produce magnetic lignin particles. The adsorbent was characterized by FTIR, XRD, $\mathrm{N}_{2}$ adsorption desorption, SEM and VSM. The mechanisms of the adsorption and desorption behavior were also investigated. This research would provide a new way to prepare magnetic materials and increase the added value of lignin.

\section{EXPERIMENTAL}

\section{Materials}

Biorefinery lignin from corncob, provided by Shandong Longlive Bio-Technology Co., Ltd, China, was used as the feedstock. Chemicals, including anhydrous lithium chloride $(\mathrm{LiCl})$, methyl orange, ferric chloride hexahydrate $\left(\mathrm{FeCl}_{3} \cdot 6 \mathrm{H}_{2} \mathrm{O}\right)$, ferrous sulfate heptahydrate $\left(\mathrm{FeSO}_{4} \cdot 7 \mathrm{H}_{2} \mathrm{O}\right)$, ammonia water, and dimethyl sulfoxide (DMSO), were purchased from Aladdin Biochemical Technology Co., LTD. (Shanghai, China). All chemicals were analytical grade and used without further purification. 


\section{Preparation of Magnetic Lignin-based Adsorbent (MLA)}

Two grams of lignin was dissolved in $80 \mathrm{~mL}$ of $\mathrm{LiCl} / \mathrm{DMSO}$ solution $(6 \%$, w/w\%). Then deionized water was gradually added to the above mixed solution under stirring conditions until the deionized water accounted for $80 \%$. The suspension was transferred to the dialysis bag (2000 Da) for dialysis in deionized water. Finally, concentrated solution was obtained after rotary evaporation.

$5.5 \mathrm{~g}$ of $\mathrm{FeCl}_{3} \cdot 6 \mathrm{H}_{2} \mathrm{O}$ and $3.4 \mathrm{~g} \mathrm{FeSO}_{4} \cdot 7 \mathrm{H}_{2} \mathrm{O}$ were added together into $100 \mathrm{~mL}$ deionized water in four-neck flask; $30 \mathrm{~mL}$ of $10 \mathrm{wt} \%$ ammonia solution was injected into the solution under vigorous stirring when the temperature of solution rose to $90{ }^{\circ} \mathrm{C}$. The color of the solution immediately changed from orange to black. The solution was heated at $90{ }^{\circ} \mathrm{C}$ in $\mathrm{pH}$ of 10 for $1.5 \mathrm{~h}$ with stirring. Concentrated solution was added into the reaction system, followed by $20 \mathrm{~mL}$ of $10 \mathrm{wt} \%$ ammonia solution. The mixture was stirred for $2 \mathrm{~h}$ at $90{ }^{\circ} \mathrm{C}$. When the reaction finished, magnetic particles were separated by a magnet and thoroughly washed with ethanol and deionized water in turn. The final products were freeze-dried.

The magnetic particles were carbonized in the tube furnace for $3 \mathrm{~h}$ at $500{ }^{\circ} \mathrm{C}$ under a $\mathrm{N}_{2}$ atmosphere. The final MLA was collected for further use.

\section{Characterization of MLA}

Different technologies were adopted to characterize the physical properties of MLA. FTIR spectra were collected in a VERTEX70 instrument (Bruker, Germany) using the $\mathrm{KBr}$ pellet technique. The molecular weight of MLA was evaluated using Agilent 1200 gel permeation chromatography (GPC) with a refraction index detector (RID). X-ray diffraction (XRD) analysis was recorded on an X-ray diffractometer (D8 Venture, Bruker, Germany) with a scanning rate of $2^{\circ} / \mathrm{min}$ from $10^{\circ}$ to $80^{\circ}$. $\mathrm{N}_{2}$ gas adsorption and desorption analysis was performed using BET analyzer (ASAP2020, Micromeritics, USA), and the specific surface area of the samples was calculated by the BET equation. The morphology of MLA was analyzed using a scanning electron microscopy (SEM, Regulus 8200, Hitachi, Japan). The magnetic property of MLA was explored by VSM equipment (7404 series, Lakeshore, USA). In order to explore the thermal stability of MLA, thermogravimetric analysis (TGA) experiments were performed in a TA Q50 thermogravimetric analyzer (TA Instrument, USA). The zeta potential of MLA was measured by Zetasizer Nano-ZS90 (Malven Instruments, UK).

\section{Adsorption Experiment}

In a typical experiment, $20 \mathrm{mg}$ of MLA was added to the methyl orange solution, and the flasks was oscillated in a water bath. MLA was removed from the solution by magnetic separation after the adsorption was completed. The concentration of methyl orange in the solution was measured with an UV spectrophotometer (Cary 5000, Agilent, USA).

\section{RESULTS AND DISCUSSION}

\section{Structural Characterization of MLA}

The FTIR spectra of lignin and MLA are shown in Fig. 1a. The peak at $1610 \mathrm{~cm}^{-1}$ is attributable to the skeletal vibration of the aromatic ring (Shao et al. 2017). The band at $830 \mathrm{~cm}^{-1}$ is assigned to the syringyl structure in lignin. An obvious absorption peak at 573 
$\mathrm{cm}^{-1}$ occurred in MLA, which belonged to the characteristic adsorption peak of $\mathrm{Fe}-\mathrm{O}$ in $\mathrm{Fe}_{3} \mathrm{O}_{4}$ (You et al. 2012). This demonstrated the formation of lignin-coated oxide particles. The FTIR result indicated that most of aromatic ring disappeared in MLA, but the $\mathrm{Fe}_{3} \mathrm{O}_{4}$ structure was retained as well as some $\mathrm{O}-\mathrm{H}$ groups after carbonization.

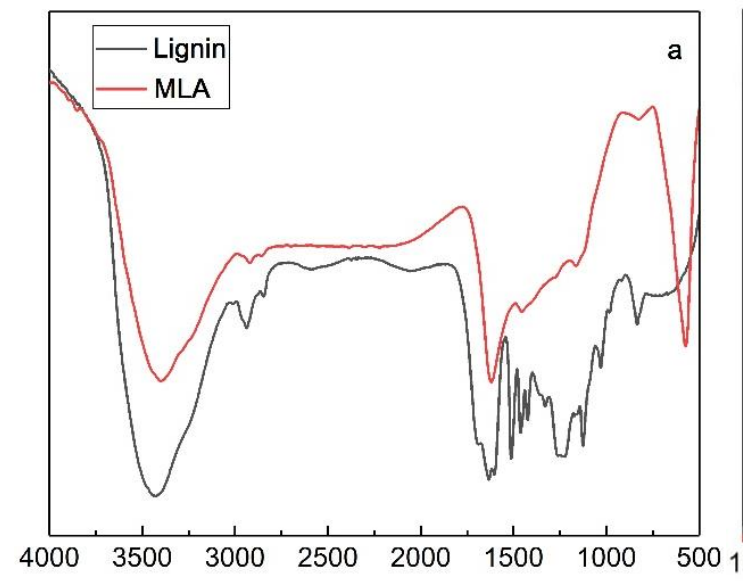

Wavenumber $\left(\mathrm{cm}^{-1}\right)$
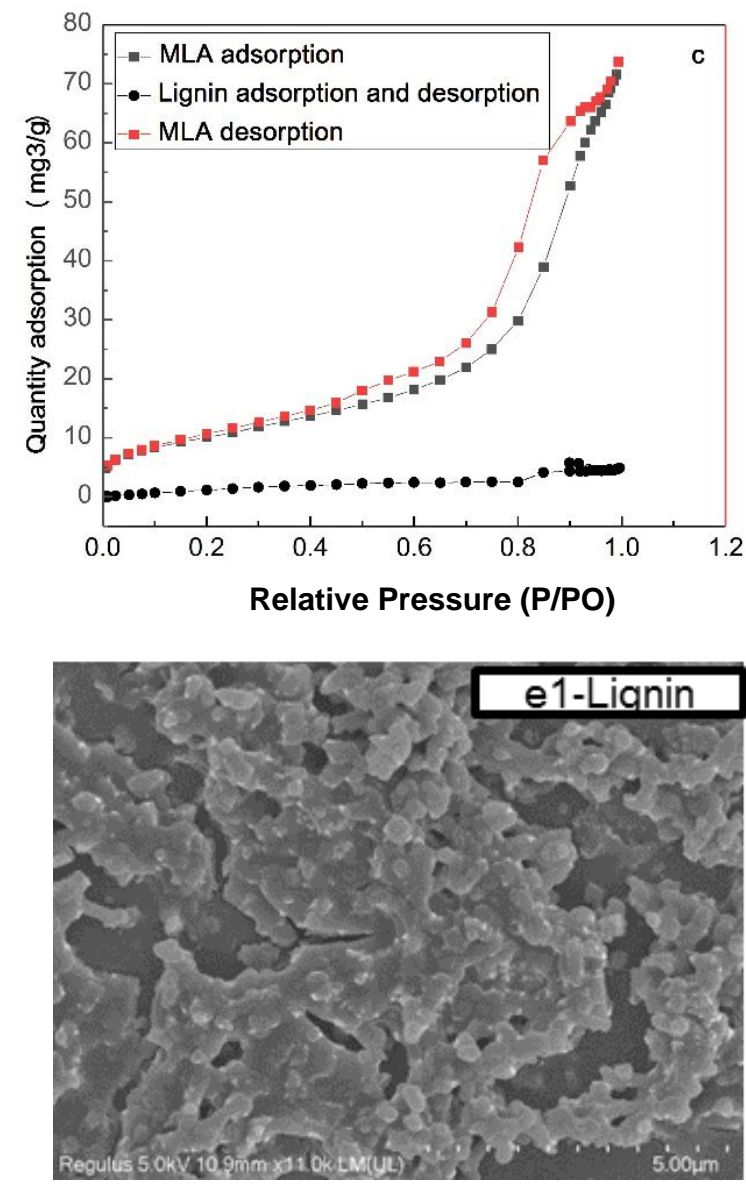

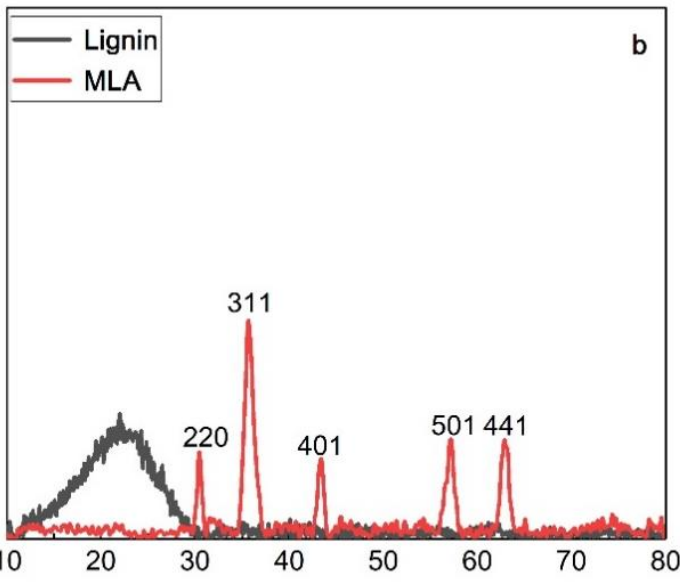

$2 \theta\left({ }^{\circ}\right)$
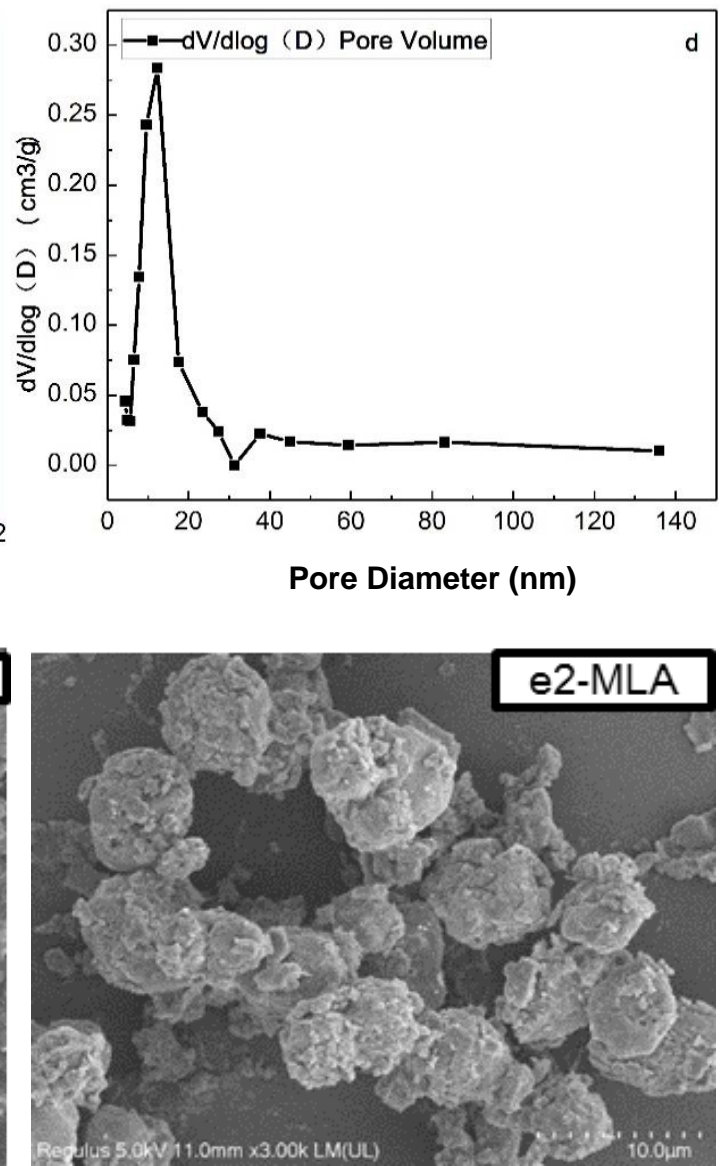

Fig. 1 (parts a to e). Characterization of lignin and MLA. (a) FTIR spectra, (b) XRD patterns, (c) $\mathrm{N}_{2}$ adsorption desorption isotherm, (d) Pore size distribution, (e) SEM images, (f) Magnetic hysteresis curves, (g) TG curves of lignin and MLA, (h) zeta potential 

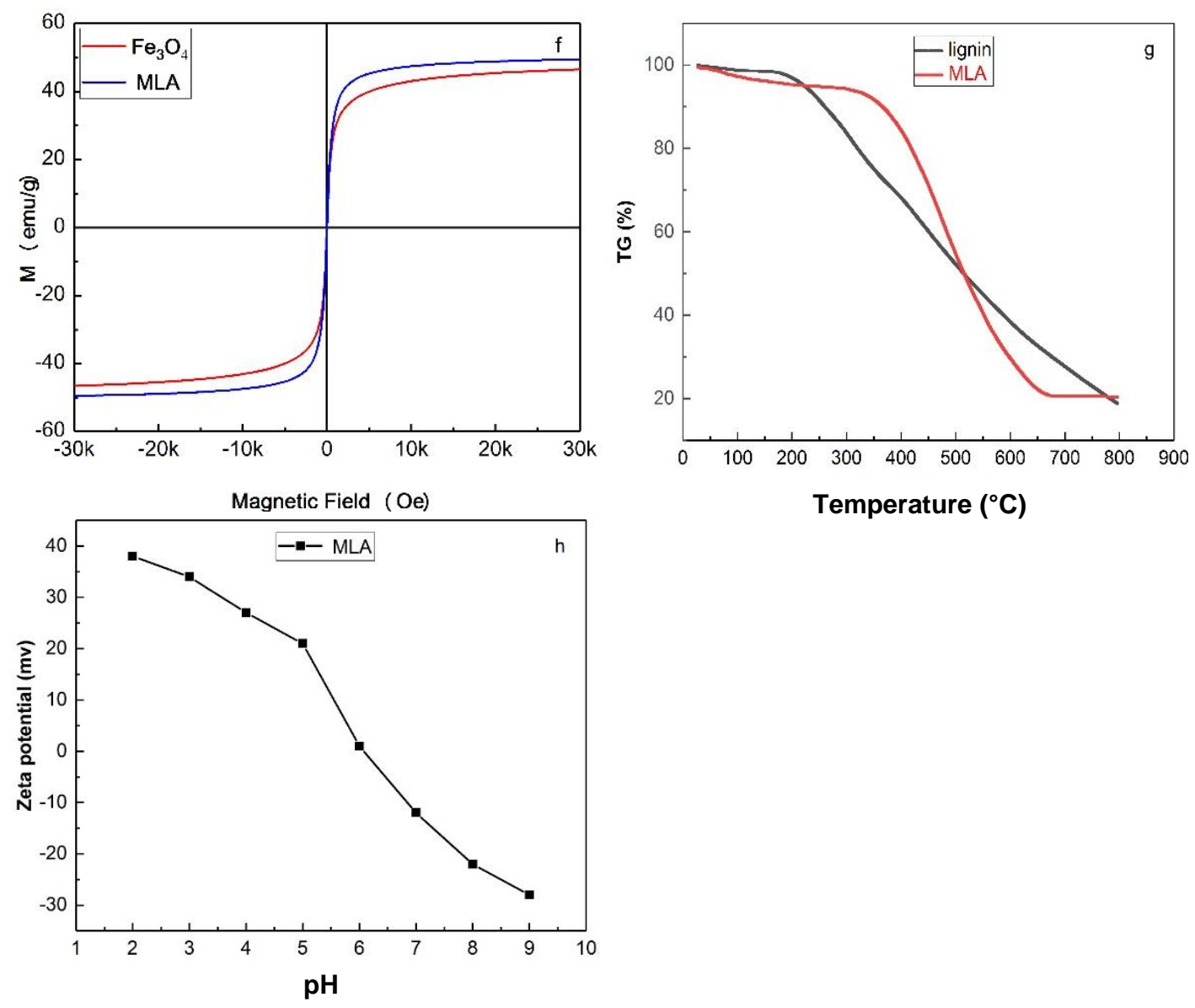

Fig. 1. Characterization of lignin and MLA. (a) FTIR spectra, (b) XRD patterns, (c) $\mathrm{N}_{2}$ adsorption desorption isotherm, (d) Pore size distribution, (e) SEM images, (f) Magnetic hysteresis curves, (g) TG curves of lignin and MLA, (h) zeta potential

The weight-average molecular weight $\left(M_{\mathrm{w}}\right)$, number-average molecular weight $\left(M_{\mathrm{n}}\right)$, and polydispersity $\left(M_{w} / M_{n}\right)$ of lignin and MLA are shown in Table 1 . It could be seen that there were no obvious changes in the molecular weight and polydispersity. This indicated that magnetic $\mathrm{Fe}_{3} \mathrm{O}_{4}$ loading had little effect on the molecular weight and polydispersity of lignin.

The XRD spectra of lignin and MLA are shown in Fig. 1b. Five diffraction characteristic peaks at 30.3, 35.5, 43.1, 57.3, and 62.3 were attributed to (220), (311), (401), (501), and (441) crystal planes respectively, which indexed to a $\mathrm{Fe}_{3} \mathrm{O}_{4}$ cubic spinel structure (Zheng et al. 2013; An et al. 2017). This demonstrated that $\mathrm{Fe}_{3} \mathrm{O}_{4}$ was contained in MLA.

The $\mathrm{N}_{2}$ adsorption-desorption isotherms and pore distribution of MLA are shown in Figs. 1c and 1d. The isotherms maintained a type IV shape with an obvious hysteresis loop, indicating that there were rich mesoporous in the structure of MLA (Sun et al. 2006). It could be calculated that the specific surface area of MLA was $42.1 \mathrm{~m}^{2} / \mathrm{g}$. The average pore size was $12.3 \mathrm{~nm}$, which belonged to mesoporous.

The SEM images are shown in Fig. 1e. A rough irregular surface and large surface area occurred in MLA, which improved the adsorption capacity.

Figure 1f shows the magnetic hysteresis loop of $\mathrm{Fe}_{3} \mathrm{O}_{4}$ and MLA. The saturation magnetization intensity of MLA was about $51.3 \mathrm{emu} / \mathrm{g}$. Almost no hysteresis loops were 
found in the magnetization, certifying the superparamagnetism of MLA (Xie et al. 2014). It can be magnetically separated from the solution due to the high magnetization values and superparamagnetic characteristics. This feature allows the reusable application of MLA as adsorbents, which is economical and sustainable.

Thermogravimetric (TG) curves of lignin and MLA, obtained at a heating rate of $10{ }^{\circ} \mathrm{C} / \mathrm{min}$, are plotted in Fig. 1g. For lignin, a much more significant weight loss was detected when temperature exceeded $200{ }^{\circ} \mathrm{C}$. Meanwhile, for MLA, a similar trend of weight loss occurred when temperature exceeded $350^{\circ} \mathrm{C}$. Furthermore, the weight of MLA remained constant after $650{ }^{\circ} \mathrm{C}$. The result suggested that MLA had better thermal stability than lignin.

The zeta potential of MLA is displayed in Fig. 2h. A zero potential point occurred at $\mathrm{pH}$ 6.0. It is clearly observed that zeta potential increased rapidly when the $\mathrm{pH}$ was decreased below 6.0, indicating the functional groups and surface of MLA were easily protonated. In addition, the zeta potential was negative under basic condition, for the reason that the ferric ions on the surface of MLA could attract $\mathrm{OH}^{-1}$.

Table 1. Molecular Weight Distribution of Lignin and MLA

\begin{tabular}{|l|l|l|l|}
\hline Sample & $M_{w}$ & $M_{n}$ & $M_{w} / M_{n}$ \\
\hline MLA & 2067 & 798 & 2.59 \\
\hline Lignin & 2247 & 896 & 2.51 \\
\hline
\end{tabular}

\section{Effect of pH on Adsorption}

The effect of solution $\mathrm{pH}$ on adsorbent performance cannot be neglected in application, which determines molecular interactions between the adsorbate and the adsorbent. $20 \mathrm{mg}$ of MLA was added into $20 \mathrm{~mL}$ of methyl orange solution $(100 \mathrm{mg} / \mathrm{L})$ and stirred for $2.5 \mathrm{~h}$ at $25{ }^{\circ} \mathrm{C}$. The $\mathrm{pH}$ of the solution was set as 1.0, 2.0, 3.0, 4.0, 5.0, 6.0, 7.0, 8.0, and 9.0. The adsorption results at different $\mathrm{pH}$ are displayed in Fig. 2.

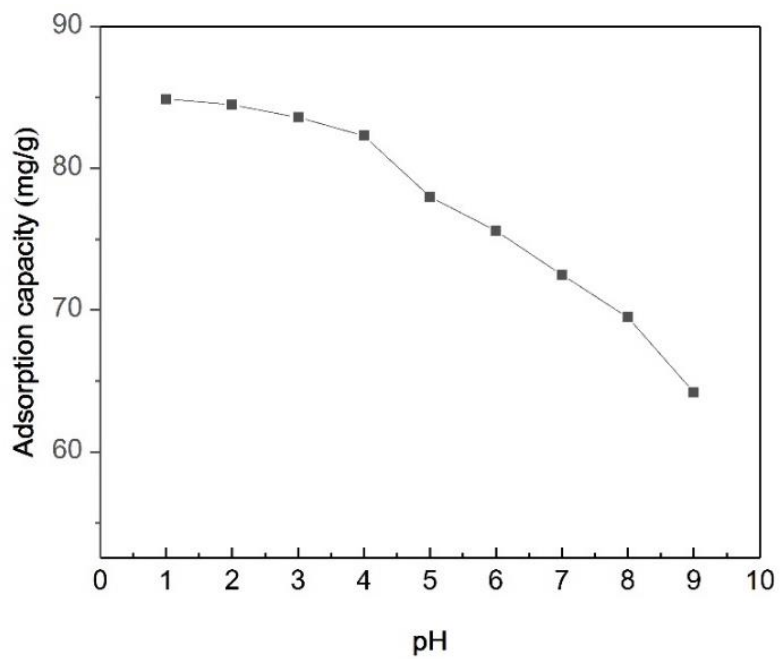

Fig. 2. The effect of $\mathrm{pH}$ on adsorption of methyl orange

The data showed that adsorption capacity decreased with the increase of $\mathrm{pH}$ value. The presence of $\mathrm{H}^{+}$promotes the adsorbent's binding with methyl orange. The surface of MLA was positively charged under acidic conditions, which could attract the sulfonic acid group of methyl orange (Nair et al. 2014; Ma et al. 2018). Under neutral condition, MLA 
still had relative large adsorption capacity, and the surface of MLA was negatively charged. This indicated that there was a pi-pi effect between MLA surface and methyl orange, which contributed to adsorption. Based on the results and operation conditions, pH 5.0 was selected as an optimized parameter for following experiments, though the adsorption capacity was larger under strong acidic conditions.

\section{Effect of Concentration of Methyl Orange on Adsorption}

MLA $(20 \mathrm{mg})$ was added into $20 \mathrm{~mL}$ of methyl orange solution with different concentrations $(20 \mathrm{mg} / \mathrm{L}$ to $140 \mathrm{mg} / \mathrm{L}$ ). The $\mathrm{pH}$ of solution was adjusted to 5 and oscillated for $2.5 \mathrm{~h}$ at $25{ }^{\circ} \mathrm{C}$. The result of adsorption capacity is displayed in Fig. 3. As the concentration of methyl orange increased, the adsorption capacity increased from 18.72 to $92.14 \mathrm{mg} / \mathrm{g}$, showing a positive correlation. The reason was that the contact chance between the adsorption sites on the surface of MLA and methyl orange increased with the increase of the concentration of methyl orange (Zhang et al. 2011). Finally, the adsorption capacity tended to be stable beyond a certain concentration, while percent adsorption decreased from $93.6 \%$ to $64.2 \%$. It could be seen that methyl orange was removed more thoroughly by MLA at lower concentration. Based on actual operation, the concentration of methyl orange in further study was set as $100 \mathrm{mg} / \mathrm{L}$.

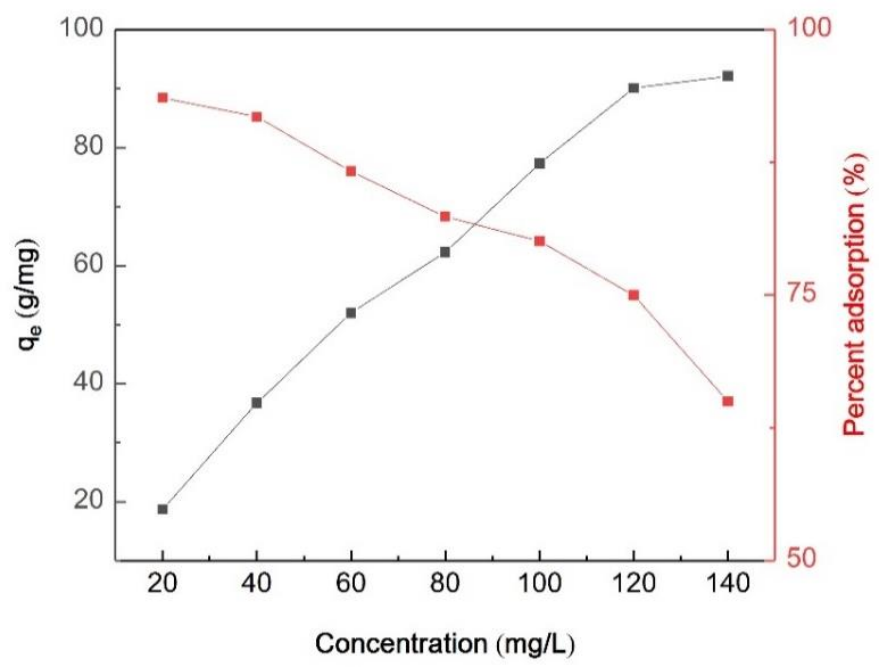

Fig. 3. Adsorption isotherm for the adsorption of methyl orange onto MLA at $25^{\circ} \mathrm{C}$

In general, the Langmuir and Freundlich models have been adopted to describe the equilibrium adsorption isotherms (Brdar et al. 2012; Feng et al. 2014).

The Langmuir adsorption equation:

$$
\frac{\mathrm{C}_{e}}{q_{e}}=\frac{\mathrm{C}_{e}}{q_{\max }}+\frac{1}{K_{L} q_{\max }}
$$

The Freundlich adsorption equation:

$$
\ln q_{e}=\ln K_{F}+\frac{1}{n} \operatorname{lnc} c_{e}
$$

In Eqs. 1 and 2, $C_{\mathrm{e}}$ is equilibrium concentration $(\mathrm{mg} / \mathrm{L}) ; q_{\mathrm{e}}$ is equilibrium adsorption capacity of MLA $(\mathrm{mg} / \mathrm{g}) ; q_{\max }$ is the maximum adsorption capacity $(\mathrm{mg} / \mathrm{g}) ; K_{\mathrm{L}}$ is the Langmuir adsorption constant $(\mathrm{L} / \mathrm{mg})$; and $K_{\mathrm{F}}$ and $1 / n$ are the Freundlich constants, correlated to the adsorption capacity and adsorption intensity, respectively. 
Table 2. Langmuir and Freundlich Isotherm Adsorption Parameters for the Adsorption of Methyl Orange

\begin{tabular}{|c|c|c|c|c|c|c|}
\hline \multirow{2}{*}{ Sample } & \multicolumn{3}{|c|}{ Langmuir Model } & \multicolumn{3}{c|}{ Freundlich Model } \\
\cline { 2 - 7 } & $q_{\max }(\mathrm{mg} / \mathrm{g})$ & $K_{\mathrm{L}}$ & $\mathrm{R}^{2}$ & $1 / n$ & $K_{\mathrm{F}}$ & $\mathrm{R}^{2}$ \\
\hline $\mathrm{MLA}$ & 85.0 & 0.0943 & 0.9872 & 0.3522 & 15.71 & 0.9422 \\
\hline
\end{tabular}
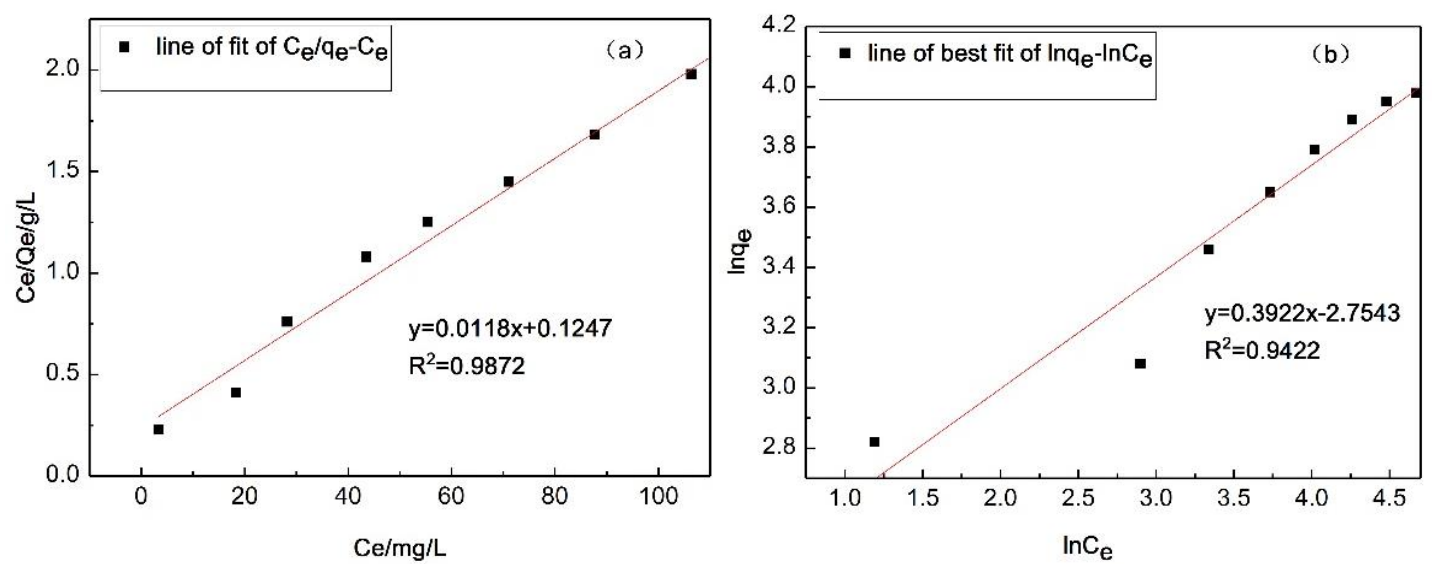

Fig. 4. Line of best fit of adsorption isotherm by (a) Langmuir equation, (b) Freundlich equation

The isotherm adsorption parameters and linear fitting curves are shown in Table 2 and Fig. 4. The Freundlich constant $(1 / n)$ represents the adsorption intensity of the adsorbent. When its value is in the range $0.1<1 / \mathrm{n} \leqslant 0.5$, the adsorbate was easy to adsorb (Luo and Zhang 2009). The value of $1 / n$ in this study was 0.3522 , manifesting that methyl orange was easily adsorbed by MLA. The coefficient of determination $\left(\mathrm{R}^{2}\right)$ of the Langmuir model was 0.9872, which was higher than that of the Freundlich model $\left(\mathrm{R}^{2}=0.9422\right)$. Based on the results, the adsorption behavior of MLA on methyl orange could be better represented by Langmuir adsorption isotherm equation. In addition, based on the calculation data, the maximum adsorption capacity was $85.0 \mathrm{mg} / \mathrm{g}$ when the concentration of methyl orange was $100 \mathrm{mg} / \mathrm{L}$.

\section{Adsorption Kinetics}

The effect of contact time on the adsorption of MLA for methyl orange was investigated. The results are displayed in Fig. 5. It can be observed that the adsorption capacity increased quickly as adsorption time increased. The adsorption mainly happened on the surface of MLA in this stage. The equilibrium time for methyl orange adsorption was about $2.5 \mathrm{~h}$. After that, the increased rate of adsorption capacity slowed down. To investigated the kinetics further, two kinetic models (pseudo-first-order and pseudosecond-order) were used to describe the adsorption process (Asthana et al. 2016).

Pseudo-first-order kinetics model:

$\ln \left(q_{e}-q_{t}\right)=\ln q_{e}-k_{1} t$

Pseudo-second-order kinetics model:

$$
\frac{t}{q_{t}}=\frac{1}{k_{2} q_{e}^{2}}+\frac{t}{q_{e}}
$$


In Eqs. 3 and 4, $q_{e}$ and $q_{t}$ are the adsorption capacity at experimental equilibrium and at time $t(\mathrm{mg} / \mathrm{g})$, respectively; $k_{1}$ is the pseudo-first-order rate constant $\left(\mathrm{min}^{-1}\right)$; and $k_{2}$ is the pseudo-second-order rate constant $(\mathrm{g} /(\mathrm{mg} \bullet \mathrm{min}))$.

The kinetic model parameters as well as correlation coefficients were calculated and listed in Table 3.

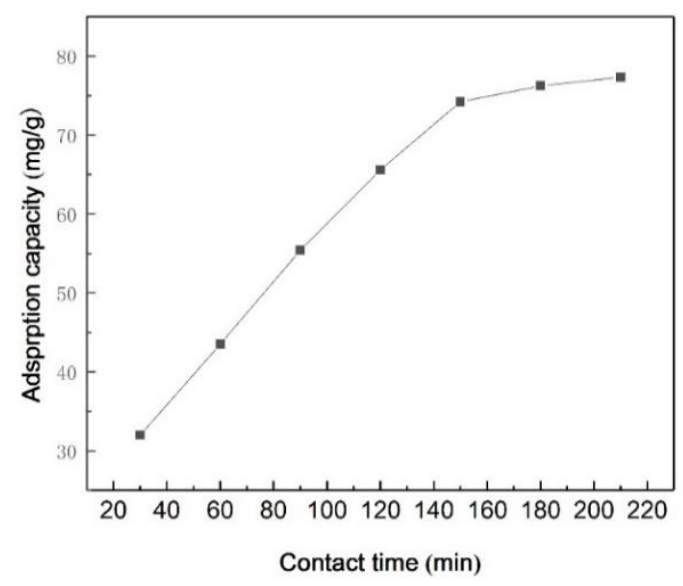

Fig. 5. Effect of contact time on the adsorption capacity of MLA for methyl orange $\left(T=25^{\circ} \mathrm{C}, \mathrm{pH}=5\right.$, methyl orange concentration $=100 \mathrm{mg} / \mathrm{L}$ )

Table 3 Parameters of Various Adsorption Kinetic Models

\begin{tabular}{|l|l|l|l|l|l|l|l|}
\hline Sample & $q_{\mathrm{e}, \mathrm{exp}}$ & \multicolumn{3}{|l|}{ Pseudo-first-order Model } & \multicolumn{3}{l|}{ Pseudo-second-order Model } \\
\cline { 3 - 8 } & $(\mathrm{mg} / \mathrm{g})$ & $k_{1}\left(\mathrm{~min}^{-1}\right)$ & $q_{\mathrm{e}, \mathrm{cal}}(\mathrm{mg} / \mathrm{g})$ & $\mathrm{R}^{2}$ & $k_{2}(\mathrm{~g} /(\mathrm{mg} \cdot \mathrm{min}))$ & $q_{\mathrm{e}, \mathrm{cal}}(\mathrm{mg} / \mathrm{g})$ & $\mathrm{R}^{2}$ \\
\hline MLA & 72.2 & 0.0207 & 64.6 & 0.9572 & $1.9 \times 10^{-4}$ & 73.0 & 0.9962 \\
\hline
\end{tabular}


Fig. 6. The line of best fit of adsorption kinetics using (a) pseudo-first-order-model, (b) pseudosecond-order-model

The adsorption capacity at experimental equilibrium $\left(q_{\mathrm{e}, \mathrm{exp}}=72.2 \mathrm{mg} / \mathrm{g}\right)$ was closer to the theoretically calculated one $\left(q_{\mathrm{e}, \mathrm{cal}}=73.0 \mathrm{mg} / \mathrm{g}\right)$, indicating that adsorption kinetics could be fit to the pseudo-second-order model well. In addition, in Fig. 6, pseudo-secondorder model provided the extremely high coefficients of determination $\left(\mathrm{R}^{2}=0.9962\right)$, which was higher than that in pseudo-first-order model $\left(\mathrm{R}^{2}=0.9572\right)$. These results supported the conclusion that the adsorption of methyl orange by MLA obeyed a pseudo-second-order model (Zhang et al. 2016). The pseudo-second-order relationship might be used to fit data 
in which some sites of adsorption take a lot longer to be filled. In the adsorption process, adsorption sites far from a pellet's outer surface were more difficult to reach, which led to a diffusion-controlled rate of adsorption (Hubbe et al. 2019).

\section{Regeneration Study}

The recycling of adsorbents is considered to be a key parameter for industrial application. Ethanol was adopted as the eluent to wash MLA which was separated in magnetic field (Fig. 7). Regenerative functions of MLA are shown in Fig 8. It could be seen that almost no decrease of adsorption ability happened after the second cycle. After four cycles of regeneration, the adsorption capacity of MLA for methyl orange was 64.0 $\mathrm{mg} / \mathrm{g}$ ( $82 \%$ of initial capacity), indicating that the great mass of adsorption sites on the adsorbent surface could be renewed. The data supported the evidence that MLA could be a sustainable adsorbent.

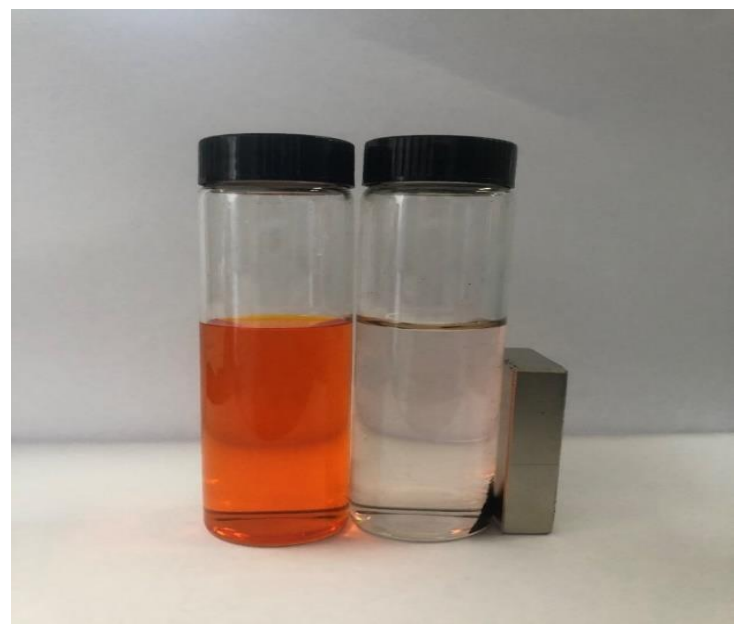

Fig. 7. The separation of MLA in magnetic field

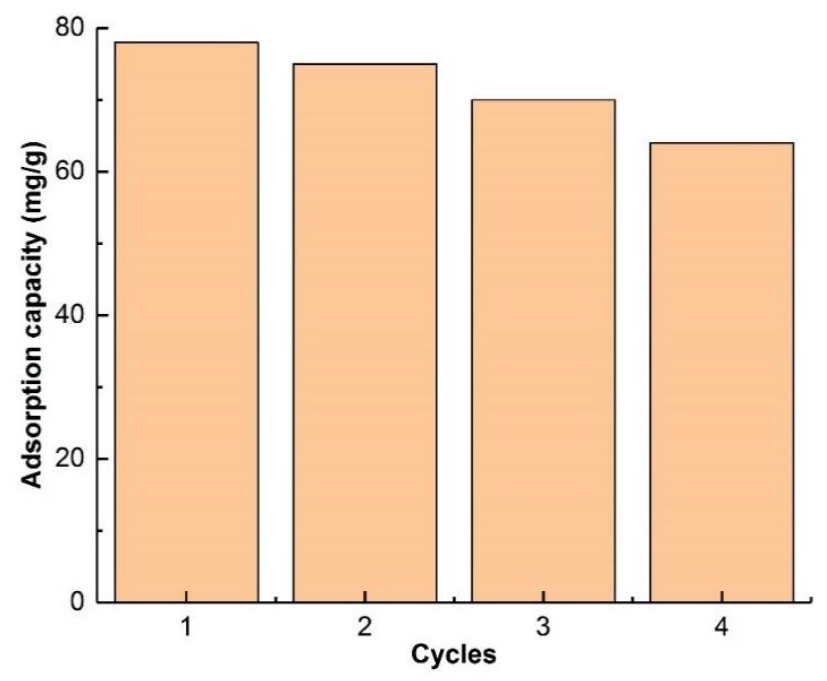

Fig. 8. The effect of cycles on the adsorption of MLA for methyl orange $\left(T=25^{\circ} \mathrm{C}\right.$, methyl orange concentration $=100 \mathrm{mg} / \mathrm{L}$, contact time $=2.5 \mathrm{~h}$ ) 


\section{CONCLUSIONS}

1. The magnetic lignin-based adsorbent (MLA) was found to be very efficient in removing methyl orange from aqueous solutions. The adsorption kinetics agreed well with the pseudo-second-order model.

2. The adsorption isotherm fitted the Langmuir model with a maximum adsorption capacity for methyl orange of $85.0 \mathrm{mg} / \mathrm{g}$ (based on the methyl orange concentration of $100 \mathrm{mg} / \mathrm{g}$ ).

3. MLA exhibited good recycling performance. After four cycles of regeneration, the adsorption capacity of MLA for methyl orange was $64.0 \mathrm{mg} / \mathrm{g}$ ( $82 \%$ of initial capacity)

\section{ACKNOWLEDGMENTS}

The authors gratefully acknowledge the National Natural Science Foundation of China (Grant No. 31770626), the Shandong Provincial Natural Science Foundation (Grant No. ZR2019BC074), the Foundation of the State Key Laboratory of Biobased Material and Green Papermaking of the Qilu University of Technology and the Shandong Academy of Science (Grant No. ZZ20190103), and the Doctoral Cooperation Foundation of Qilu University of Technology and the Shandong Academy of Science (Grant No. 2018BSHZ0025) for financial support of this research.

\section{REFERENCES CITED}

An, X. Y., Cheng, D., Dai, L., Wang, B. B., Ocampo, H. J., Nasrallah, J., Jia, X., Zou, J. J., Long, Y. D., and Ni, Y. H. (2017). "Synthesis of nano-fibrillated cellulose/magnetite/titanium dioxide ( $\mathrm{NFC@} \mathrm{Fe}_{3} \mathrm{O}_{4} @ \mathrm{TNP}$ ) nanocomposites and their application in the photocatalytic hydrogen generation," Applied Catalysis B:

Environmental 206, 53-64. DOI: 10.1016/j.apcatb.2017.01.021

Aro, T., and Fatehi, P. (2017). "Production and application of lignosulfonates and sulfonated lignin," ChemSusChem 10(9), 1861-1877. DOI: 10.1002/cssc.201700082

Asthana, A., Verma, R., Singh, A. K., and Susan, M. A. B. H. (2016). "Glycine functionalized magnetic nanoparticle entrapped calcium alginate beads: a promising adsorbent for removal of $\mathrm{Cu}$ (II) ions," Journal of Environmental Chemical Engineering 4(2), 1985-1995. DOI: 10.1016/j.jece.2016.03.024

Banerjee, P., Mukhopadhyay, A., and Das, P. (2019). "Graphene oxide-nanobentonite composite sieves for enhanced desalination and dye removal," Desalination 451231240. DOI: 10.1016/j.desal.2017.06.010

Brdar, M., Šćiban, M., Takači, A., and Došenović, T. (2012). "Comparison of two and three parameters adsorption isotherm for Cr (VI) onto kraft lignin," Chemical Engineering Journal 183108-111. DOI: 10.1016/j.cej.2011.12.036

Carneiro, P. A., Umbuzeiro, G. A., Oliveira, D. P., and Zanoni, M. V. B. (2010). "Assessment of water contamination caused by a mutagenic textile effluent/dyehouse effluent bearing disperse dyes," Journal of Hazardous Materials 174(1-3), 694-699. DOI: 10.1016/j.jhazmat.2009.09.106 
Chen, B., Zhao, X., Liu, Y., Xu, B., and Pan, X. (2015). "Highly stable and covalently functionalized magnetic nanoparticles by polyethyleneimine for $\mathrm{Cr}$ (VI) adsorption in aqueous solution," RSC Advances 5(2), 1398-1405. DOI: 10.1039/c4ra10602d

Essandoh, M., and Garcia, R. A. (2018). "Efficient removal of dyes from aqueous solutions using a novel hemoglobin/iron oxide composite," Chemosphere 206, 502512. DOI: 10.1016/j.chemosphere.2018.04.182

Feng, Q., Cheng, H., Li, J., Wang, P., and Xie, Y. (2014). “Adsorption behavior of basic dye from aqueous solution onto alkali extracted lignin," BioResources 9(2), 36023612.

Geng, J., Gu, F., and Chang, J. (2019). "Fabrication of magnetic lignosulfonate using ultrasonic-assisted in situ synthesis for efficient removal of Cr (VI) and Rhodamine B from wastewater," Journal of Hazardous Materials 375, 174-181. DOI: 10.1016/j.jhazmat.2019.04.086

González-López, M. E., Robledo-Ortíz J. R., Rodrigue D., and Pérez-Fonseca A. A. (2020). "Highly porous lignin composites for dye removal in batch and continuousflow systems," Materials Letters 263, 127289. DOI: 10.1016/j.matlet.2019.127289

Guo, X., Zhang, S., and Shan, X. (2008). “Adsorption of metal ions on lignin," Journal of Hazardous Materials 151(1), 134-142. DOI: 10.1016/j.jhazmat.2007.05.065

Hubbe, M. A., Azizian, S., and Douven, S. (2019). "Implications of apparent pseudosecond-order adsorption kinetics onto cellulosic materials. A review," BioResources 14(3), 7582-7626. DOI: 10.15376/biores.14.3.7582-7626

Kaykhaii, M., Sasani, M., and Marghzari, S. (2018). "Removal of dyes from the environment by adsorption process," Chemical and Materials Engineering 6(2), 3135. DOI: $10.13189 / \mathrm{cme} .2018 .060201$

Kazzaz, A. E., Feizi, Z. H., and Fatehi, P. (2019). "Grafting strategies for hydroxy groups of lignin for producing materials," Green Chemistry 21(21), 5714-5752. DOI: 10.1039/C9GC02598G

Li, J., Li, H., Yuan, Z., Fang, J., Chang, L., Zhang, H., and Li, C. (2019). "Role of sulfonation in lignin-based material for adsorption removal of cationic dyes," International Journal of Biological Macromolecules 1351171-1181. DOI: 10.1016/j.ijbiomac.2019.06.024

Li, X., He, Y., Sui, H., and He, L. (2018). “One-step fabrication of dual responsive lignin coated $\mathrm{Fe}_{3} \mathrm{O}_{4}$ nanoparticles for efficient removal of cationic and anionic dyes," Nanomaterials 8(3), 162. DOI: 10.3390/nano8030162

Liu, L., Gao, Z. Y., Su, X. P., Chen, X., Jiang, L., and Yao, J. M. (2015). “Adsorption removal of dyes from single and binary solutions using a cellulose-based bioadsorbent," ACS Sustainable Chemistry \& Engineering 3(3), 432-442. DOI: $10.1021 / \mathrm{sc} 500848 \mathrm{~m}$

Liu, M., Chen, Q., Lu, K., Huang, W.-Q., Lü, Z.-H., Zhou, C.-M., Yu, S.-C., and Gao, C.G. (2017). "High efficient removal of dyes from aqueous solution through nanofiltration using diethanolamine-modified polyamide thin-film composite membrane," Separation and Purification Technology 173, 135-143. DOI: 10.1016/j.seppur.2016.09.023

Luo, X., and Zhang, L. (2009). "High effective adsorption of organic dyes on magnetic cellulose beads entrapping activated carbon," Journal of Hazardous Materials 171(13), 340-347. DOI: 10.1016/j.jhazmat.2009.06.009 
Ma, Y., Zheng, D., Mo, Z., Dong, R., and Qiu, X. (2018). "Magnetic lignin-based carbon nanoparticles and the adsorption for removal of methyl orange," Colloids and Surfaces A 559, 226-234. DOI: 10.1016/j.colsurfa.2018.09.054

Nair, V., Panigrahy, A., and Vinu, R. (2014). "Development of novel chitosan-lignin composites for adsorption of dyes and metal ions from wastewater," Chemical Engineering Journal 254, 491-502. DOI: 10.1016/j.cej.2014.05.045

Shao, L., Zhang, Q., You, T., Zhang, X., and Xu, F. (2018). "Microwave-assisted efficient depolymerization of alkaline lignin in methanol/formic acid media," Bioresource Technology 264, 238-243. DOI: 10.1016/j.biortech.2018.05.083

Shao, L., Zhang, X., Chen, F., and Xu, F. (2017). "Fast pyrolysis of Kraft lignins fractionated by ultrafiltration," Journal of Analytical and Applied Pyrolysis 128, 2734. DOI: 10.1016/j.jaap.2017.11.003

Shuai, L., Amiri, M. T., Questell-Santiago, Y. M., Héroguel, F., Li, Y.-D., Kim, H., Meilan, R., Chapple, C., Ralph, J., and Luterbacher, J. S. (2016). "Formaldehyde stabilization facilitates lignin monomer production during biomass depolymerization," Science 354(6310), 329-333. DOI: 10.1126/science.aaf7810

Song, K., Xu, H., Xu, L., Xie, K., and Yang, Y. (2017). “Cellulose nanocrystal-reinforced keratin bioadsorbent for effective removal of dyes from aqueous solution," Bioresource Technology 232, 254-262. DOI: 10.1016/j.biortech.2017.01.070

Sun, Z., Wang, L., Liu, P., Wang, S., Sun, B., Jiang, D., and Xiao, F. S. (2006). "Magnetically motive porous sphere composite and its excellent properties for the removal of pollutants in water by adsorption and desorption cycles," Advanced Materials 18(15), 1968-1971. DOI: 10.1002/chin.200644016

Supanchaiyamat, N., Jetsrisuparb, K., Knijnenburg, J. T., Tsang, D. C., and Hunt, A. J. (2019). "Lignin materials for adsorption: Current trend, perspectives and opportunities," Bioresource Technology 272, 570-581. DOI: 10.1016/j.biortech.2018.09.139

Wang, X., Jiang, C., Hou, B., Wang, Y., Hao, C., and Wu, J. (2018). “Carbon composite lignin-based adsorbents for the adsorption of dyes," Chemosphere 206, 587-596. DOI: 10.1016/j.chemosphere.2018.04.183

Xie, Y., Yan, B., Xu, H., Chen, J., Liu, Q., Deng, Y., and Zeng, H. (2014). "Highly regenerable mussel-inspired $\mathrm{Fe}_{3} \mathrm{O}_{4} @$ polydopamine-Ag core-shell microspheres as catalyst and adsorbent for methylene blue removal," ACS Applied Materials \& Interfaces 6(11), 8845-8852. DOI: 10.1021/am501632f

Xu, C., Arancon, R. A. D., Labidi, J., and Luque, R. (2014). "Lignin depolymerisation strategies: towards valuable chemicals and fuels," Chemical Society Reviews 43(22), 7485-7500. DOI: $10.1039 / \mathrm{c} 4 \mathrm{cs} 00235 \mathrm{k}$

Yagub, M. T., Sen, T. K., Afroze, S., and Ang, H. M. (2014). "Dye and its removal from aqueous solution by adsorption: A review," Advances in Colloid and Interface Science 209, 172-184. DOI: 10.1016/j.cis.2014.04.002

Yang, R., Li, D., Li, A., and Yang, H. (2018). "Adsorption properties and mechanisms of palygorskite for removal of various ionic dyes from water," Applied Clay Science 151, 20-28. DOI: 10.1016/j.clay.2017.10.016

You, L., Xu, S., Ma, W.-F., Li, D., Zhang, Y.-T., Guo, J., Hu, J. J., and Wang, C.-C. (2012). "Ultrafast hydrothermal synthesis of high quality magnetic core phenolformaldehyde shell composite microspheres using the microwave method," Langmuir 28(28), 10565-10572. DOI: 10.1021/la3023562 
Zhai, R., Hu, J., Chen, X., Xu, Z., Wen, Z., and Jin, M. (2020). "Facile synthesis of manganese oxide modified lignin nanocomposites from lignocellulosic biorefinery wastes for dye removal," Bioresource Technology 315, 123846. DOI: 10.1016/j.biortech.2020.123846

Zhang, J., Lin, X., Luo, X., Zhang, C., and Zhu, H. (2011). "A modified lignin adsorbent for the removal of 2, 4, 6-trinitrotoluene," Chemical Engineering Journal 168(3), 1055-1063. DOI: 10.1016/j.cej.2011.01.083

Zhang, S., Zhou, Y., Nie, W., and Song, L. (2012). "Preparation of $\mathrm{Fe}_{3} \mathrm{O}_{4} /$ chitosan/poly (acrylic acid) composite particles and its application in adsorbing copper ion (II)," Cellulose 19(6), 2081-2091. DOI: 10.1007/s10570-012-9783-4

Zhang, S., Wang, Z., Zhang, Y., Pan, H., and Tao, L. (2016). "Adsorption of methylene blue on organosolv lignin from rice straw," Procedia Environmental Sciences 31, 311. DOI: 10.1016/j.proenv.2016.02.001

Zhang, Y., Ni, S., Wang, X., Zhang, W., Lagerquist, L., Qin, M., Willfor, S., Xu, C., and Fatehi, P. (2019). "Ultrafast adsorption of heavy metal ions onto functionalized lignin-based hybrid magnetic nanoparticles," Chemical Engineering Journal 372, 8291. DOI: 10.1016/j.cej.2019.04.111

Zheng, J., Dong, Y., Wang, W., Ma, Y., Hu, J., Chen, X., and Chen, X. (2013). "In situ loading of gold nanoparticles on $\mathrm{Fe}_{3} \mathrm{O}_{4} @ \mathrm{SiO}_{2}$ magnetic nanocomposites and their high catalytic activity," Nanoscale 5(11), 4894-4901. DOI: 10.1039/c3nr01075a

Article submitted: January 22, 2021; Peer review completed: March 28, 2021; Revisions completed: June 3, 2021; Published: June 11, 2021.

DOI: 10.15376/biores.16.3.5436-5449 